\title{
Evaluation of road safety level in school areas: the case of the city of Thessaloniki, Greece
}

\author{
S. Basbas, C. Konstantinidou \& A. Giorgou \\ Faculty of Rural and Surveying Engineering, \\ Aristotle University of Thessaloniki, Greece
}

\begin{abstract}
The pupils' trips to and from school, have been investigated thoroughly by many researchers all over the world due to the safety risk imposed to the students by the vehicular traffic. All proposals that have been made by the researchers have aimed at the improvement of the walking environment in terms of safety, accessibility, security etc. The overall target is to reduce traffic flows and speed near school areas and to further improve the environment. This paper attempts to evaluate the service facilities provided near elementary school areas in the city of Thessaloniki, Greece. In the framework of this research, a survey was carried out in various areas of the city. Each survey area has different land use and transport system characteristics. The examination of the road safety level near schools was based on the use of two tools: the Pedestrian Quality Inspection which is one of the developments of COST 358: Pedestrians' Quality Needs and the Dover, Kohl \& Partners, Town Planning, and Chael, Cooper \& Associates P.A. Architecture, Design Guidelines for Pedestrian-Friendly Neighborhood Schools. The survey provides information on pupils' trips from home to school and also on the characteristics of the current walking infrastructure near school areas in order to evaluate the road safety level and to propose measures so that walking from home to school becomes friendlier, safer, and more accessible for the pupils.
\end{abstract}

Keywords: road safety, school, walking.

\section{Introduction}

Children consist one of the most vulnerable road user groups; those users are likely to suffer when in conflict with cars, buses and other large vehicles. Vulnerable road users as a term may also be used to describe users of the road 
network whose mobility is in some way reduced or who face barriers to their movement.

These road users include; pedestrians, elderly people, children, people with small children, people with mobility disabilities, people whose mobility is impaired due to pregnancy or to carrying any types of heavy luggage [1]. Especially for children, walking is vital to their mobility, particularly for short trips and carrying out essential daily tasks.

The increase of traffic volume itself leads to the increase of parents' fear for their children's trips made on foot. As a result, every day more and more children are driven to school by car.

This paper attempts to address and evaluate service facilities provided in elementary school areas in terms of safety and accessibility. The identification of facilities is based on a survey which was carried out in the vicinity of three elementary schools located in different Municipalities of the city of Thessaloniki, Greece. Each survey area has different land use and transport system characteristics. Additionally, proposals in order to improve the road safety level and the accessibility level near school areas are also included in the paper.

\section{Road safety near school areas}

School is the place which attracts a large number of children on a daily basis. For this reason safe and accessible routes from home to school and vice-versa are required. School vicinity often become more and more unsafe mainly due to the presence of high traffic volumes and therefore many parents prefer to use their private cars in order to take their children to school.

According to Centres for Disease Control (CDC) in Great Britain, 85\% of children arrive at school by car while a small percentage $(13 \%)$ of students arrive at school on foot or by bicycle [2]. The same results arise from the survey Home-to-School Transportation EDOT 1992 where in the city of Florida one out of six children goes to school on foot or by bicycle. The rest of them go to school by bus or by car [3] causing traffic jam and unsafe conditions near school areas.

As it is mentioned above, children belong to Vulnerable Road Users and one of the special characteristics of pupils is their unexpected behaviour while using the road network (i.e. cross the road simultaneously with vehicles, non-use of pedestrian crossings, etc). In addition pupils have not the ability to estimate the speed of vehicles, something which results to the cause of accidents near school areas.

According to the Institute of Transportation Engineers (ITE) "Design and Safety of Pedestrian Facilities" the majority of drivers do not reduce their speed near school areas unless they see the police, a school traffic policeman or children in front of them. During the last years, special attention was given to children and their trips made on foot, especially near school areas. A friendly walking school environment is an area which encourages safe walking from home to school [4].

It must be mentioned that "....children and young people are 100 times more likely to be killed by road users than by strangers...." $[5,6]$. According to recent 
predictions, [7], the road accidents will constitute the third reason of death in 2020. In terms of research for children's accidents, in a class of 30 children two of them are expected to be killed or injured in a road accident before their 16 years of age [8]. The most common types of accident among pedestrian/children at the age of six are the following [9]:

- During their exit to the road network

- During their entrance to crossings

- While crossing the road in front of a vehicle

- While crossing a road with a high number of lanes

- Playing on the road

- During their boarding/ disembarkation from the bus

- While moving behind the vehicle which moves backwards

\section{Students' trips from home to school}

The schools which were selected for the current research are located in areas of the Thessaloniki Metropolitan Area with different land use and transport system characteristics as it has been mentioned above and for this reason they are divided in three categories [10]:

- one elementary school in the centre of the Municipality of Thessaloniki (population of the Municipality: 375.246 inhabitants).

- one elementary school in the Municipality of Eleftherio Kordelio, Thessaloniki Metropolitan Area (population of the Municipality: 74.254 inhabitants).

- one elementary school located in the Municipality of Oreokastro, Thessaloniki Metropolitan Area (population of the Municipality: 25.231 inhabitants).

The selected school in the centre of the Municipality of Thessaloniki was the $36^{\text {th }}$ elementary school, an area which is characterized by high volume of traffic, high volume of pedestrians and high building density. The second school located in the western part of the city of Thessaloniki (Municipality of Eleftherio Kordelio) was the $8^{\text {th }}$ elementary school and the $13^{\text {th }}$ special school, an area which has been characterized by rapid building development over recent years, high concentration of pedestrians and medium traffic volumes. Finally one school was examined in the Municipality of Oreokastro $\left(1^{\text {st }}\right.$ and $4^{\text {th }}$ elementary school), an area which is characterized by low building density, high volume of pedestrians and low traffic volumes.

As far as the $36^{\text {th }}$ elementary school of the Municipality of Thessaloniki is concerned, the majority of pupils arrived at school accompanied by their parents on foot while a low percentage of pupils arriving by car. Regarding the behavior of pupils while walking, it was observed that the majority of them obeyed the Highway Code regulations and they have used the pedestrian crossings.

As far as the $8^{\text {th }}$ elementary school of the Municipality of Eleftherio Kordelio is concerned, pupils arrived at school only on foot (some accompanied by their 
parents or by their friends) while students of the $13^{\text {rd }}$ special school arrive at school by special bus. The majority of pupils did not use pedestrian crossings but they crossed the road together with their friends at random points. In addition, the poor geometric characteristics of the pavements, the illegal roadside parking, the rubbish buckets, the absence of ramps etc, made walking environment unfriendly.

With reference to the $1^{\text {st }}$ and $4^{\text {th }}$ elementary school of the Municipality of Oreokastro, the majority of pupils arrived at school by car with their parents except for a low percentage of pupils who arrive at school alone on foot because they lived very close to school. A low percentage of pupils arrived at school by school bus.

It can be easily noticed that the majority of pupils in the Municipalities of Thessaloniki and Oreokastro arrived at school accompanied by their parents. According to pupils' behavior during their trips on foot, it was observed that the children who walked alone followed the Highway Code regulations and used pedestrian crossings and pavements while the pupils who walked with their friends moved on the road and rarely used pedestrian crossings. It should be mentioned that in some cases it was observed that the absence of pedestrian crossings and the large width of roads made walking environment unsafe for pedestrians and especially for the pupils.

\section{Evaluation of walking ability}

In order to evaluate the quality of walking environment near school areas two methodologies are used. The first methodology is the Pedestrian Quality Inspection which is one of the developments of COST 358: Pedestrians' Quality Needs is used [11]. The walkability checklist is a tool for recording the walking environment in terms of safety, accessibility, legislation and policy.

The second methodology is based on the use of the "Design Guidelines for Pedestrian-Friendly Neighborhood Schools" which was developed by Dover, Kohl \& Partners, Town Planning, and Chael, Cooper \& Associates P.A. Architecture [12]. "The purpose of these guidelines is to give stakeholders involved with various aspects of school location and construction issues some specific factors to consider making schools pedestrian-friendly. The guidelines group these factors into three broad areas: Neighborhood Guidelines, School Site Design Guidelines and School Building Design Guidelines" [12].

The rating of road safety level near school areas was according to the method. It must be mentioned at this point that not all of the proposed checklist elements of the method were used in the research but only a part of them which is modified.

The total sum of weights of the different elements was decided by the authors to be equal to one and the weight of each element was also given by the authors of this paper. The results are presented in Tables 1 to 3 (maximum score of the total final rating is 4.55 ).

The results from the evaluation of walking ability near school areas determine that the walking ability is at an acceptable level near school areas with adequate 
pavement network, numerous pedestrian crossings and measures for speed reduction. As it can be easily noticed, the area near the $36^{\text {th }}$ elementary school of the Municipality of Thessaloniki is characterized by better conditions (3.63) for walking in terms of safety and accessibility than the other examined elementary schools despite the fact that this area is also characterized by the existence of high traffic volume.

Table 1: Elements affecting road safety level in $36^{\text {th }}$ elementary school of the municipality of Thesaloniki.

\begin{tabular}{|c|c|c|c|c|}
\hline $\mathbf{a} / \mathbf{a}$ & Elements & $\begin{array}{c}\text { Rating } \\
(\mathbf{0}-\mathbf{5})\end{array}$ & Weight & $\begin{array}{c}\text { Final } \\
\text { Rating }\end{array}$ \\
\hline 1 & Road connection & 4 & 0.10 & 0.40 \\
\hline 2 & $\begin{array}{c}\text { Complete pavements' } \\
\text { network }\end{array}$ & 5 & 0.25 & 1.25 \\
\hline 3 & Road trees & 5 & 0.04 & 0.20 \\
\hline 4 & $\begin{array}{c}\text { Specified pedestrian } \\
\text { crossings }\end{array}$ & 3 & 0.25 & 0.75 \\
\hline 5 & Required speed level & 3 & 0.25 & 0.75 \\
\hline 6 & Observation-Security & 4 & 0.02 & 0.08 \\
\hline 7 & Location & 4 & 0.04 & 0.16 \\
\hline 8 & $\begin{array}{c}\text { Bikes Parking near school } \\
\text { entrance }\end{array}$ & 0 & 0.04 & 0 \\
\hline 9 & $\begin{array}{c}\text { Visible entrance from } \\
\text { public area }\end{array}$ & 4 & 0.01 & 0.04 \\
\hline \multicolumn{3}{|c|}{ TOTAL } & & $\mathbf{3 . 6 3}$ \\
\hline
\end{tabular}

Table 2: Elements affecting road safety level in $8^{\text {th }}$ elementary school of the municipality of Eleftherio Kordelio.

\begin{tabular}{|c|c|c|c|c|}
\hline $\mathbf{a} / \mathbf{a}$ & Elements & $\begin{array}{c}\text { Rating } \\
(\mathbf{0}-\mathbf{5})\end{array}$ & Weight & $\begin{array}{c}\text { Final } \\
\text { Rating }\end{array}$ \\
\hline 1 & Road connection & 4 & 0.10 & 0.40 \\
\hline 2 & $\begin{array}{c}\text { Complete pavements' } \\
\text { network }\end{array}$ & 2 & 0.25 & 0.50 \\
\hline 3 & Road trees & 3 & 0.04 & 0.12 \\
\hline 4 & $\begin{array}{c}\text { Specified pedestrian } \\
\text { crossings }\end{array}$ & 1 & 0.25 & 0.25 \\
\hline 5 & Required speed level & 4 & 0.25 & 1 \\
\hline 6 & Observation-Security & 3 & 0.02 & 0.06 \\
\hline 7 & Location & 4 & 0.04 & 0.16 \\
\hline 8 & $\begin{array}{c}\text { Bikes Parking near school } \\
\text { entrance }\end{array}$ & 0 & 0.04 & 0 \\
\hline 9 & $\begin{array}{c}\text { Visible entrance from } \\
\text { public area }\end{array}$ & 3 & 0.01 & 0.03 \\
\hline \multicolumn{3}{|c|}{ TOTAL } & $\mathbf{2 . 5 2}$ \\
\hline
\end{tabular}


Table 3: $\quad$ Elements affecting road safety level in $1^{\text {st }}$ and $4^{\text {th }}$ elementary school of the municipality of Oreokastro.

\begin{tabular}{|c|c|c|c|c|}
\hline $\mathbf{a} / \mathbf{a}$ & Elements & $\begin{array}{c}\text { Rating } \\
(\mathbf{0}-\mathbf{5})\end{array}$ & Weight & $\begin{array}{c}\text { Final } \\
\text { Rating }\end{array}$ \\
\hline 1 & Road connection & 4 & 0.1 & 0.40 \\
\hline 2 & $\begin{array}{c}\text { Complete pavements } \\
\text { network }\end{array}$ & 2 & 0.25 & 0.50 \\
\hline 3 & Road trees & 4 & 0.04 & 0.16 \\
\hline 4 & $\begin{array}{c}\text { Specified pedestrian } \\
\text { crossings }\end{array}$ & 1 & 0.25 & 0.25 \\
\hline 5 & Required speed level & 3 & 0.25 & 0.75 \\
\hline 6 & Observation-Security & 4 & 0.02 & 0.08 \\
\hline 7 & Location & 3 & 0.04 & 0.12 \\
\hline 8 & $\begin{array}{c}\text { Bikes Parking near school } \\
\text { entrance }\end{array}$ & 0 & 0.04 & 0 \\
\hline 9 & $\begin{array}{c}\text { Visible entrance from } \\
\text { public area }\end{array}$ & 5 & 0.01 & 0.05 \\
\hline \multicolumn{4}{|c|}{ TOTAL } \\
\hline
\end{tabular}

According to the Pedestrian Quality Inspection method the most important findings concerning the evaluation of walking ability near school areas in terms of design, safety, accessibility and pedestrian facilities are the following:

- The walking infrastructure is adequate near the $36^{\text {th }}$ elementary school of Thessaloniki while the other two elementary schools have very poor pedestrian facilities.

- Absence of pedestrian crossings and appropriate parking areas (for vehicles) in general.

- Unpredictable pupils' behavior.

- The speed limit near school areas is $30 \mathrm{~km} / \mathrm{h}$ and,

- Traffic signals observed only near the $36^{\text {th }}$ elementary school.

In terms of drivers, it was noticed that the majority of them ignore the pedestrian facilities and the school area which involves high volume of pupils making their walking environment more and more unfriendly. According to the level of safety, the highest level was observed near the $36^{\text {th }}$ elementary school area where the high concentration of land uses enforces the feeling of safety and security. Also the pedestrianisation schemes near school areas increase the feeling of safety for pedestrians and especially for pupils. The school area near the $1^{\text {st }}$ and the $4^{\text {th }}$ elementary schools of the Municipality of Oreokastro are considered friendlier for walking due to low building density, high numbers of trees and absence of noise pollution compared to the rest of the examined schools.

The pedestrian network near $36^{\text {th }}$ elementary school area in the centre of the Municipality of Thessaloniki is ignored in many cases by the drivers. The high 
concentration of pupils during the arrival and departure time led drivers to behave inpatient and thus increase the possibility of road accidents.

The $8^{\text {th }}$ elementary school of the Municipality of Eleftherio Kordelio is characterized by almost the same conditions as the $36^{\text {th }}$ elementary school of the Municipality of Thessaloniki. The absence of ramps, the absence of pedestrian crossings, the high volume of traffic and the illegal parked cars in these areas are increases the possibility of a road accident and as result reduces the level of safety for pupils and their attendants.

The area near $1^{\text {st }}$ and the $4^{\text {th }}$ elementary schools of the Municipality of Oreokastro is characterized by the absence of pavements, absence of pedestrian crossings and ramps. The high concentration of cars out of the school exit and the illegal parked cars near school cause difficulties to the road network access and as result increase the danger of an accident.

\section{Discussion}

The difficulties which pupils experience during their trips make walking environment more and more unfriendly in many cases. As a result, parents prefer to use their private car for their children's trips rather than leave their children to walk alone to school near areas which are characterized from high traffic volumes and poor pedestrian facilities.

Transport planners should take into consideration a series of measures in order to improve walking environment such as: adequate speed limits (i.e., $30 \mathrm{~km} / \mathrm{h}$ or less), pedestrianisation schemes, pedestrian crossings (zebra crossing for being the crossing in school entrance more visible from the drivers), safety zones, ramps, width narrowness, chicanes, Woonerf areas (in the Municipalities of Eleftherio-Kordelio and Oreokastro), special signing to warn drivers about school and other infrastructure for children, use of Intelligent Transport Systems (ITS) like Variable Message Signs (VMS), CCTV systems etc. On the other hand, the local authorities should take into consideration measures to make walking environment especially near school areas safe, friendlier and more secure for the students so that parents would trust school walking environment and allow their children to go to school on foot.

As an overall remark it seems that the road safety level near the examined school areas can be further improved. There is need for further research on more school areas so that important results for the road safety level near school areas are extracted. In addition, a method should be adopted in order to evaluate road safety and accessibility level near school areas at national level. Only then the walking environment near school areas in terms of safety and accessibility will be improved and pupils will feel free to go to school alone, free to play, free to live in an area friendly to their needs.

\section{References}

[1] Apostolidis, Ch, Gaitazi, X. \& Kitsou, E. Evaluation of pedestrians characteristics in the centre of Thessaloniki, Greece, Diploma Thesis, 
Supervisor: S. Basbas, Department of Transportation and Hydraulic Engineering, Faculty of Rural and Surveying Engineering, Aristotle University of Thessaloniki, 2008.

[2] Maryland Bicycle and Pedestrian Advisory Committee, Maryland Department of Transportation, Safe Routes to School Guidebook, Maryland.

[3] Assessing Walking Conditions with Audits, available at: http://www.walkinginfo.org/problems/audits.cfm

[4] Basbas S., Kokkalis A. \& Konstantinidou C., Perception of the traffic safety level provided in elementary school areas, Proc. of the $15^{\text {th }}$ International Conference: Urban Transport and the Environment in the $21^{\text {st }}$ Century - Urban Transport XV, ed. C.A. Brebbia, Wessex Institute of Technology, Bologna, Italy, Published by WIT Press, 2009.

[5] Prezza, M., Alparone, F.R., Cristallo, C. \& Luigi, S., Parental perception of social risk and of positive potentiality of outdoor autonomy for children: The development of two instruments, Journal of Environmental Psychology, 25(4), pp. 437-453, 2005.

[6] Sustrans. Safe routes to school, Newsletter, 14. Bristol: Sustrans, 2001

[7] Tsourlakis, K., Pedestrians and Road Safety in Greece, Proc.of the $3^{\text {rd }}$ Conference on Road Safety, Patras, Greece, 2005.

[8] Department of Environment, Transport and the Regions, 1998b, Department of Transport, Road Accidents in Great Britain: The Casualty Report, HMSO, London, UK, 1997.

[9] Otak., Pedestrian Facilities Guidebook: Incorporating Pedestrians Into Washington's Transportation System, Washington State Department of Transportation, Puget Sound Regional Council, County Road Administration Board, Association of Washington Cities, Washington, USA, 1997.

[10] Giorgou, A., Evaluation of pedestrian infrastructure near school areas in the city of Thessaloniki, Greece, M.Sc. Thesis, Supervisor: S. Basbas, Department of Transportation and Hydraulic Engineering, Faculty of Rural and Surveying Engineering, Aristotle University of Thessaloniki, 2010.

[11] Gerlach, J., Pedestrian Quality Audits and Inspections - more than a part of the new EU-Directive on Road Safety Infrastructure Management, COST 358 Pedestrians' Quality Needs Final Report, Part B, B5 Policy Process, B.5.6. Pedestrian Quality Audits, pp. 83- 112, 2010.

[12] Dover, Kohl \& Partners, Town Planning, and Chael, Cooper \& Associates P.A. Architecture Design Guidelines for Pedestrian-Friendly Neighborhood Schools, http://www.oregon.gov 